\title{
Epidemiological characteristics and influential factors of hand, foot, and mouth disease reinfection in Wuxi, China, 2008-2016
}

\author{
Chao Shi ${ }^{1 \dagger}$, Juan Liu ${ }^{1+}$, Ping Shi ${ }^{1}$, Hong $\mathrm{Ji}^{2}$, Yuan Shen ${ }^{1 *}$ and Yan-Hua Qian ${ }^{1 *}$
}

\begin{abstract}
Background: Hand, foot, and mouth disease (HFMD) is a viral disease caused by human enteroviruses. Although HFMD reinfection is common, studies investigating this phenomenon are insufficient.

Methods: The present study focused on HFMD reinfection in Wuxi from 2008 to 2016 using surveillance system data. Results: Of 107,677 cases included in the study, 6470 cases were classified as reinfections. The overall reinfection rate was $6.01 \%$ (6.37\% male and 5.48\% female patients), which decreased with increasing age $\left(x^{2}=1125.477, p<0.001\right)$. The rate was 6.17 and $5.79 \%$ in urban and rural areas, respectively, and 7.83 and $5.98 \%$ of the cases were severe and mild, respectively. Multivariate logistic regression analysis showed that male sex, younger age, residence in an urban area, and severe disease were risk factors for HFMD reinfection. The case-severity rate in secondary infection cases was lower than that in non-reinfection cases (odds ratio $0.675,95 \%$ confidence interval 0.526-0.866).
\end{abstract}

Conclusions: Boys younger than 4 years of age living in urban areas were more prone to reinfection. Specific health education and intervention should be developed to protect these susceptible populations.

Keywords: Hand, Foot, And mouth disease, Reinfection, Epidemiology

\section{Background}

Hand, foot, and mouth disease (HFMD) is a common viral disease usually affecting infants and children, but it can also affect adults. It is characterised by fever, mouth ulcers, and vesicles on the hands, feet, or hips [1,2]. HFMD is a highly contagious disease caused by a group of human enteroviruses; enterovirus 71 (EV71) and coxsackievirus A16 (CoxA16) are considered the primary pathogens $[3,4]$. The incubation period of HFMD is 3-7 days, and patients generally recover in 7-10 days [5]. The disease is a mild, self-limiting disorder, and most affected individuals can recover without complications. However, some patients may progress to develop a severe syndrome including myocarditis, neuronal pulmonary oedema, and aseptic

\footnotetext{
* Correspondence: wxcdcshy@163.com; wxcdcjkb@sina.cn

${ }^{+}$Chao Shi and Juan Liu contributed equally to this work.

'Wuxi Center for Disease Control and Prevention, Wuxi 214023, Jiangsu, China

Full list of author information is available at the end of the article
}

meningitis, leading to fulminant cardiorespiratory failure or even death $[6,7]$.

Epidemics of HFMD have escalated in the Asia-Pacific region since the 1990s, especially in East Asia and Southeast Asia, including Malaysia, Taiwan (China), Singapore, and Mainland China [8-11]. In 1997, 29 patients died in Malaysia, and in 1998, a large epidemic occurred in Taiwan, where a severe form of the disease was reported in 405 patients, 78 of whom died $[9,10]$. The largest Asia-Pacific pandemic was reported in China in 2008, when an outbreak of HFMD occurred in Fuyang, north of the Anhui Province, resulting in 22 deaths [12]. Thus, HFMD became an important public health issue in Mainland China and was categorised as a class $\mathrm{C}$ notifiable infectious disease by the Ministry of Health of China on 2 May 2008. Since then, medical institutions have been required to report HFMD cases within $24 \mathrm{~h}$.

(C) The Author(s). 2018 Open Access This article is distributed under the terms of the Creative Commons Attribution 4.0 International License (http://creativecommons.org/licenses/by/4.0/), which permits unrestricted use, distribution, and reproduction in any medium, provided you give appropriate credit to the original author(s) and the source, provide a link to the Creative Commons license, and indicate if changes were made. The Creative Commons Public Domain Dedication waiver (http://creativecommons.org/publicdomain/zero/1.0/) applies to the data made available in this article, unless otherwise stated. 
Owing to a lack of cross-protection among different virus subtypes, HFMD reinfection is quite common [13, 14], which increases the incidence of HFMD and the burden of HFMD on the public health system. However, there are currently insufficient studies on reinfection. The aim of the present study on reinfection in Wuxi was to explore the epidemiological features and factors influencing reinfection.

\section{Methods}

\section{Data collection}

Presently, HFMD is reported as a statutorily notifiable infectious disease, through clinical diagnoses or laboratory-confirmed cases. Data on HFMD cases from 2 May 2008 to 31 December 2016 were extracted from the National Infectious Disease Surveillance System according to the date of onset and the patient's current address, including name, sex, age, birth date, phone number, name of parents, address, case classification (clinical or laboratory), severity (severe or mild), date of diagnosis, death status, and virus type (EV71, CoxA16, or other enterovirus) for laboratory-confirmed cases.

\section{Case definitions}

The diagnostic criteria of HFMD was based on the Hand Foot and Mouth Disease Clinic Guidelines (2010 edition) issued by the Ministry of Health of China. A clinically diagnosed case was defined as a patient with vesicular rash on hands, feet, mouth, or buttocks, with or without fever, whereas a laboratory-diagnosed case was defined as a clinically diagnosed case with laboratory evidence of enterovirus infection (EV71, CoxA16, or other enterovirus) detected by reverse transcriptase polymerase chain reaction or virus isolation.

Cases were classified as severe, either by clinical or laboratory diagnosis, if the patients presented with any neurological complications, cardiopulmonary complications, or both. Otherwise, they were classified as mild. The reinfection cases were defined as patients who were infected with HFMD at least twice from 2008 to 2016, and the non-reinfection cases were defined as patients who were infected with HFMD only once.

\section{Reinfected case screening criteria}

The screening criteria for reinfected cases included: 1) the patient's name was the same; 2) > 17 days between the two dates of diagnosis; 3) more than one item common among the birth dates, parent's name, phone number, and current address. If only one item was the same, the information was checked with the patient's guardians.

\section{Statistics}

Categorical variables are presented as numbers and percentages, and continuous variables as median and interquartile range (IQR). The chi-square test was used to stratify comparisons of reinfection rate, and the chi-square test for trend was applied to analyse the incidence of infection with respect to age. Independent risk factors of HFMD reinfection were assessed using logistic regression analysis. Variables significant in the univariate analysis were included in a multivariate model. Analyses were performed with SPSS version 11.0 (SPSS, Chicago, IL, USA). All testing was two-sided, and a $p$ value $<0.05$ was considered statistically significant.

\section{Results}

\section{General patient information}

Of the 107,677 cases of HFMD reported from 2008 to 2016 in Wuxi, 6470 cases were identified as reinfections. The reinfection rate was $6.01 \%$, with 6109 patients infected twice (5.67\%), 346 patients infected three times (0.32\%), 14 patients infected four times $(0.0013 \%)$, and one patient infected five times $(0.0001 \%)$. Of all the non-reinfection HFMD cases, 1635 were classified as severe, with five deaths. On the other hand, 128 of the reinfection HFMD cases were severe, but no deaths were reported.

The reinfection rates in different groups are presented in Table 1. The reinfection rates in male and female patients were 6.37 and $5.48 \%$, respectively. The reinfection rate in children aged under 1 year of age was $9.65 \%$ and decreased with increasing age $\left(x^{2}=1125.477, p<0.001\right)$. The reinfection rate in children younger than 4 years of age was significantly higher than that in children over 4 years of age, with children under 4 years of age accounting for $86.82 \%$ of primary infections. For the different status, the reinfection rate was highest in the scattered children (7.24\%). The reinfection rate was higher in urban areas $(6.17 \%)$ than in rural areas (5.79\%). The reinfection rate was $7.83 \%$ for the severe cases and $5.98 \%$ for the mild cases.

\section{Seasonal distribution and time interval of reinfection}

The seasonal distributions of the primary infection, secondary infection, and non-reinfection cases were similar. There were two peaks, which occurred in the seasonal months of May to July and November to December annually (Fig. 1).

In patients who were infected twice, the median time interval between the two infections was 13 (IQR 7-24) months. In patients who were infected three times, the median time intervals were 10 (IQR 5-17) and 11 (IQR 5.75-20) months between the previous two infections and the latter two infections, respectively. In patients who were infected four times, the median time intervals were 9.5 (IQR 8.5-14.5), 7.5 (IQR 3-11.75) and 11 (IQR 4-19.25) months, respectively. In patients who were infected five times, the median time intervals of reinfection were $5,16,2$, and 12 months respectively. For the different age groups $(0,1,2,3,4$, and 5 years $)$, the 
Table 1 Repeated infection rate of HFMD population of different features in Wuxi city

\begin{tabular}{|c|c|c|c|c|c|c|}
\hline Characteristics & Case $(n)$ & Reinfection (n) & Non-Reinfection (n) & Refection rate (\%) & $x^{2}$ & $P$ \\
\hline Sex & & & & & 36.686 & $<0.001$ \\
\hline Male & 63,671 & 4058 & 59,613 & 6.37 & & \\
\hline Female & 44,006 & 2412 & 41,594 & 5.48 & & \\
\hline Age (year) & & & & & 1138.277 & $<0.001$ \\
\hline 0 & 7087 & 684 & 6403 & 9.65 & & \\
\hline 1 & 28,202 & 2397 & 25,805 & 8.50 & & \\
\hline 2 & 20,745 & 1377 & 19,368 & 6.64 & & \\
\hline 3 & 20,814 & 1159 & 19,655 & 5.57 & & \\
\hline 4 & 15,134 & 589 & 14,545 & 3.89 & & \\
\hline$\geq 5$ & 15,695 & 264 & 15,431 & 1.65 & & \\
\hline status & & & & & 572.368 & $<0.001$ \\
\hline Scattered children & 67,122 & 4857 & 62,265 & 7.24 & & \\
\hline Kindergartens children & 36,024 & 1581 & 34,443 & 4.39 & & \\
\hline School students & 4149 & 32 & 4117 & 0.77 & & \\
\hline Others & 382 & 0 & 382 & 0 & & \\
\hline Residence & & & & & 6.729 & 0.009 \\
\hline Rural & 45,397 & 2627 & 42,770 & 5.79 & & \\
\hline Urban & 62,280 & 3843 & 58,437 & 6.17 & & \\
\hline Clinical classification & & & & & 9.738 & 0.002 \\
\hline Mild & 106,042 & 6342 & 99,700 & 5.98 & & \\
\hline Severe & 1635 & 128 & 1507 & 7.83 & & \\
\hline
\end{tabular}

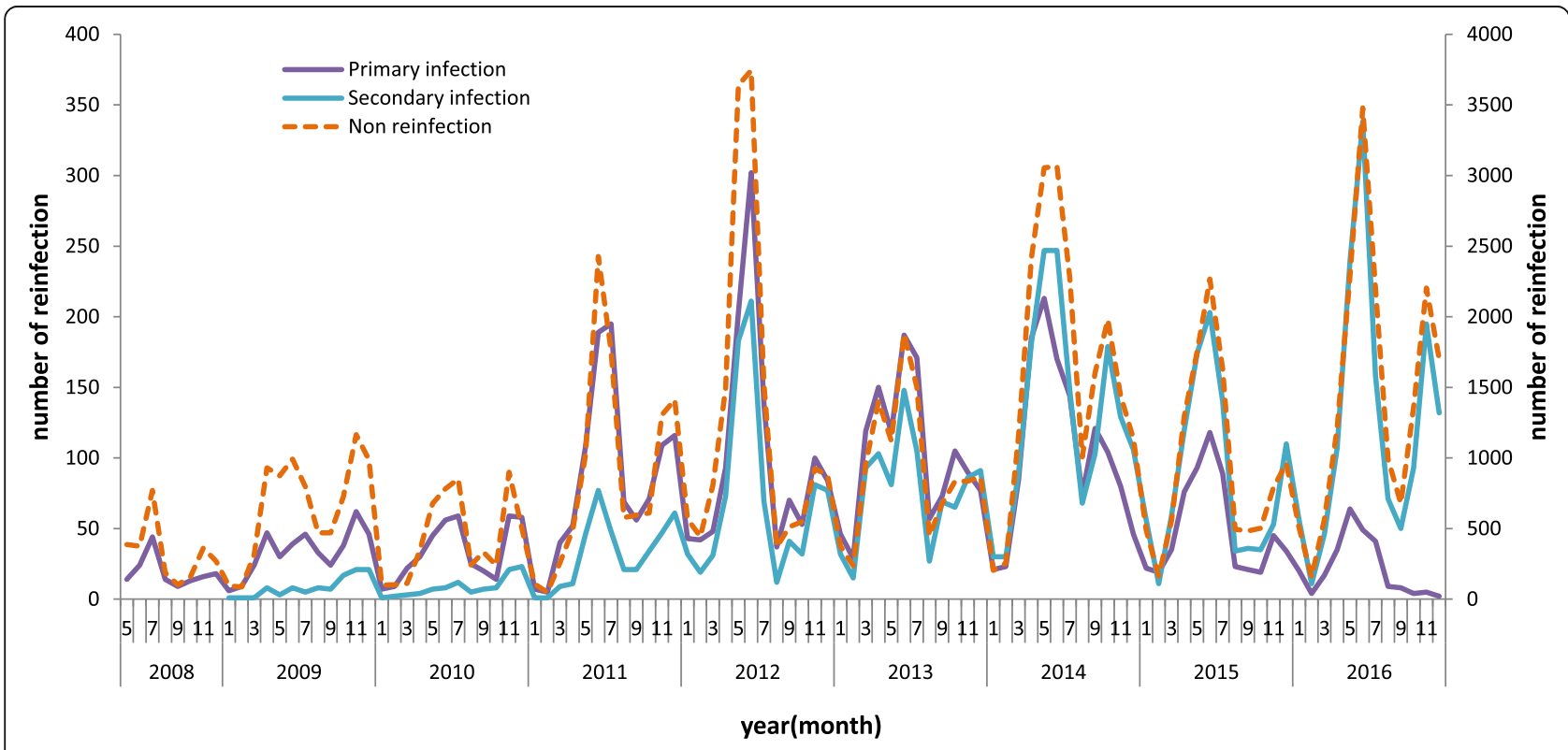

Fig. 1 Seasonal distributions of the primary and secondary infections and non-reinfection 
proportions of cases in which the time interval between the primary and secondary infections was within 2 years were $74.12,73.84,78.65,80.93,81.32$, and $87.12 \%$, respectively (Fig. 2).

\section{Relevant factors and factors influencing reinfection}

Sex, age, status, residence, and clinical classification were relevant factors for HFMD reinfection (Table 1). From the multivariate regression analysis, sex, age, and residence were found to have a significant influence on reinfection $(p<0.05)$, with male sex, younger age, and living in an urban area being risk factors of HFMD reinfection. The detailed results are listed in Table 2.

\section{Clinical classification and virus subtype of reinfection}

Of all the reinfection cases, 128 were classified as severe. Among these, 65 severe cases occurred during the second infection. The case-severity rate in the primary infection cases (1.98\%) was higher than that in both the second infection cases (1.01\%) [odds ratio (OR) 1.969, 95\% confidence interval (CI) 1.458-2.660), and non-reinfection cases (1.49\%) (OR 1.329, 95\% CI 1.107-1.594); however, the case-severity rate in secondary infection cases was lower than that of the non-reinfection cases (OR 0.675, 95\% CI 0.526-0.866) (Table 3).

Of all the reinfection cases, 478 were laboratory-diagnosed cases, of which 229 were tested during only the primary infection, 240 cases during only the second infection, and 19 cases during both infections. The proportion of patients infected with CoxA16 in the primary infection cases $(25.76 \%)$ was lower than that in the non-reinfection cases (36.16\%) (OR 0.613, 95\% CI 0.452-0.830). However, the proportion of patients infected with other enteroviruses in the primary infection cases (25.76\%) was
Table 2 Multivariate Logistic regression analysis of influencing factors of HFMD reinfection in Wuxi city

\begin{tabular}{lllll}
\hline Factors & $\beta$ & wald & OR $(95 \%$ Cl) & $P$ \\
\hline $\begin{array}{l}\text { Sex } \\
\text { Female }\end{array}$ & & & & \\
$\quad$ Male & 0.158 & 35.114 & $1.171(1.111-1.234)$ & $<0.001$ \\
Age (year) & & & & \\
0 & 1.721 & 405.358 & $5.591(4.728-6.610)$ & $<0.001$ \\
1 & 1.582 & 408.741 & $4.865(4.173-5.672)$ & $<0.001$ \\
2 & 1.298 & 276.805 & $3.662(3.142-4.267)$ & $<0.001$ \\
3 & 1.054 & 205.244 & $2.869(2.484-3.314)$ & $<0.001$ \\
4 & 0.649 & 68.821 & $1.915(1.642-2.232)$ & $<0.001$ \\
$\geq 5$ & & & 1.000 & \\
Residence & & & & $<0.001$ \\
Urban & 0.111 & 17.663 & $1.117(1.061-1.176)$ & \\
Rural & & & 1.000 & 0.05 \\
Clinical classification & & & \\
Mild & & & 1.000 & \\
Severe & 0.189 & 3.969 & $1.208(1.003-1.455)$ & \\
\hline & & & & \\
\hline
\end{tabular}

higher than that in the non-reinfection cases (16.95\%) (OR 1.701, 95\% CI 1.249-2.315) (Table 4).

Of the 19 patients who had both primary and secondary laboratory test results (Table 5), two were infected with EV71 and three with CoxA16 in both infections. Both patients who were infected with EV71 were aged 1 year, with infections occurring in April and July 2015 and in June 2010 and January 2013, respectively. Of three patients who were infected with CoxA16, the first was a 2-year-old boy, with infections occurring in August 2013 and April 2014. The second and third were 4-year-old-boys, with the infections occurring in March

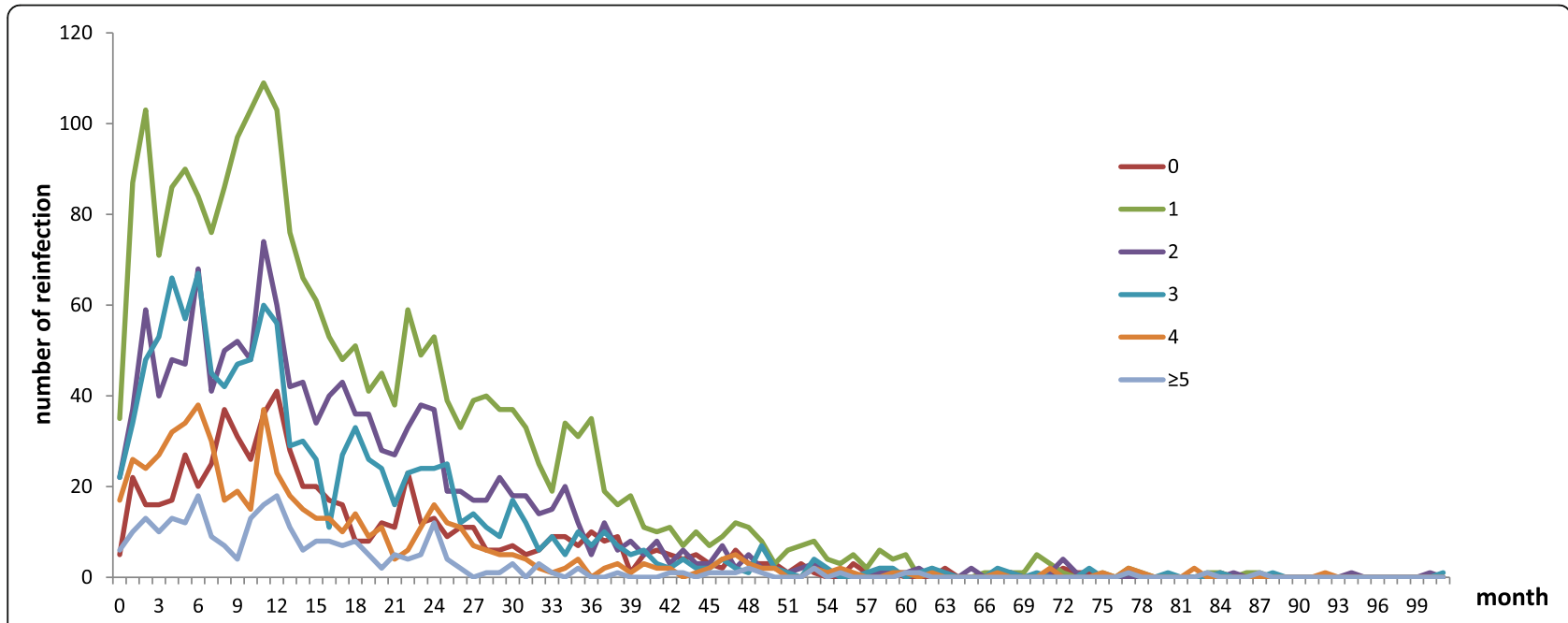

Fig. 2 Time intervals between primary and secondary infections in different age groups 
Table 3 The case-severity rate in different groups

\begin{tabular}{lllllll}
\hline Groups & Severe $(n)$ & Mild $(n)$ & Case-severe rate $(\%)$ & OR $(95 \% \mathrm{Cl})$ & $x^{2}$ & $p$ \\
\hline Reinfection cases & & & & $1.969(1.458-2.660)$ & 20.263 & $<0.001^{\mathrm{a}}$ \\
$\quad$ Primary infection & 128 & 6342 & 1.98 & $1.329(1.107-1.594)$ & 9.406 & $0.002^{\mathrm{b}}$ \\
Second infection & 65 & 6405 & 1.01 & $0.675(0.526-0.866)$ & 9.674 & $0.002^{c}$ \\
Non-reinfection cases & 1507 & 99,700 & 1.49 & 1.000 & \\
\hline
\end{tabular}

${ }^{\text {aThe }} \mathrm{P}$ value was primary infection group compares with second infection group

${ }^{\mathrm{b}}$ The $P$ value was primary infection group compares with non-reinfection group

${ }^{\mathrm{C}}$ The $P$ value was second infection group compares with non-reinfection group

2015 and June 2015 and in September 2015 and August 2016, respectively.

\section{Discussion}

The HFMD reinfection rate was $6.01 \%$ in Wuxi during 2008 to 2016, which is higher than that in Anhui Province from 2008 to 2013 [14]. Regional differences and a longer investigation period in Wuxi may have accounted for the discrepancy. However, our results are similar to a study in Fujian Province [15]. Most of the reinfection cases were patients who were infected twice $(94.42 \%)$, with one patient being infected five times in 3 years. Our results also demonstrated that the HFMD reinfection rate in boys was higher than that in girls, which is in accordance with the incidence of HFMD [16]. This may be attributed to the more active lifestyle of boys compared with girls, making them prone to touching objects polluted by infected children [14].

The present study revealed the reinfection rate decreased with increasing age, and the reinfection rate in children younger than 4 years was significantly higher than that in children over 4 years, with children under 4 years of age accounting for $86.82 \%$ of primary infection cases. Ji et al. [17] indicated that the seroprevalence rate of anti-EV71 and anti-CoxA16 gradually increased with age and reached a peak in 4-year-olds. Moreover, we found the median time interval between reinfection was 13 (IQR 7-24) months, and therefore, children under 4 years of age were more prone to reinfection within 1-2 years after the first HFMD infection.
Descriptive analysis revealed that HFMD reinfection mainly existed in scattered and kindergarten children, with the reinfection rate in the scattered children being higher than that in the other statuses. One possible reason was that the scattered children were young and had not yet developed proper personal hygiene, suggesting the need for families, and particularly caretakers, to pay attention to the personal and environmental hygiene of children. In addition, we observed that the reinfection rate was higher in urban areas, which may be attributed to the high population density and increased floating population in these urban areas.

Multivariate analysis results indicated that male sex, younger age, living in an urban area, and severe disease were risk factors of HFMD reinfection. According to the results, boys younger than 4 years, living in urban areas, and classified as having a severe first infection may be deemed a population very susceptible to reinfection. Therefore, parents or guardians need to pay close attention to the signs of HFMD. In addition, administrations need to develop targeted health education for susceptible populations of reinfection. The seasonal distributions of primary infection, secondary infection, and non-reinfection cases were similar. Our results demonstrated that during HFMD prevalence, children, especially the population susceptible to reinfection, should be monitored, even if they have been previously infected.

The case-severity rate of the primary infection was highest for different infection statuses. However, the

Table 4 The objects pathogenic distribution in different groups

\begin{tabular}{|c|c|c|c|c|c|c|c|c|c|c|}
\hline \multirow[t]{3}{*}{ Groups } & \multirow{3}{*}{$\begin{array}{l}\text { Laboratory } \\
\text { diagnosed }\end{array}$} & \multicolumn{9}{|c|}{ Virus subtypes } \\
\hline & & \multicolumn{3}{|l|}{ EV71 } & \multicolumn{3}{|l|}{ CoxA16 } & \multicolumn{3}{|l|}{ Other } \\
\hline & & n (\%) & $P$ & OR (95\%Cl) & n (\%) & P & OR $(95 \% \mathrm{Cl})$ & n (\%) & $P$ & OR $(95 \% \mathrm{Cl})$ \\
\hline Reinfection cases & & & $0.567^{a}$ & $\begin{array}{l}1.112(0.773- \\
1.598)\end{array}$ & & $0.073^{a}$ & $\begin{array}{l}0.694(0.465- \\
1.035)\end{array}$ & & $0.206^{a}$ & $\begin{array}{l}1.319(0.858- \\
2.027)\end{array}$ \\
\hline Primary infection & 229 & $111(48.47)$ & $0.641^{b}$ & $\begin{array}{l}1.066(0.816- \\
1.392)\end{array}$ & 59 (25.76) & $0.001^{b}$ & $\begin{array}{l}0.613(0.452- \\
0.830)\end{array}$ & $59(25.76)$ & $0.122^{b}$ & $\begin{array}{l}1.289(0.933- \\
1.781)\end{array}$ \\
\hline Second infection & 240 & $110(45.83)$ & $0.751^{c}$ & $\begin{array}{l}0.958(0.738- \\
1.246)\end{array}$ & $80(33.33)$ & $0.376^{c}$ & $\begin{array}{l}0.883(0.669- \\
1.164)\end{array}$ & $50(20.83)$ & $0.001^{c}$ & $\begin{array}{l}1.701(1.249- \\
2.315)\end{array}$ \\
\hline $\begin{array}{l}\text { Non-reinfection } \\
\text { cases }\end{array}$ & 3711 & $1740(46.89)$ & & 1.000 & $1342(36.16)$ & & 1.000 & 629 (16.95) & & 1.000 \\
\hline
\end{tabular}

${ }^{a}$ The $P$ value was primary infection group compares with second infection group

${ }^{b}$ The $P$ value was primary infection group compares with non-reinfection group

${ }^{\mathrm{C}}$ The $\mathrm{P}$ value was second infection group compares with non-reinfection group 
Table 5 Pathogenic results in subjects whose pathogens were detected in two infections

\begin{tabular}{lll}
\hline Primary infection & Secondary infection & Number \\
\hline EV71 & EV71 & 2 \\
EV71 & COXA16 & 5 \\
EV71 & Other enteroviruses & 1 \\
COXA16 & EV71 & 4 \\
COXA16 & COXA16 & 3 \\
Other enteroviruses & EV71 & 2 \\
Other enteroviruses & COXA16 & 2 \\
\hline
\end{tabular}

case-severity rate of the second infection was lower than that of non-infection (OR $0.675,95 \%$ CI $0.526-0.866$ ). This trend may be attributed to the increased age of patients during the second reinfection or possibly a suboptimal acquired immune protection from the initial primary infection.

The proportion of patients infected with CoxA16 in primary infection cases was lower than that in non-reinfection cases (OR 0.613, 95\% CI 0.452-0.830). However, the proportion of patients infected with other enteroviruses in primary infection cases was higher than that in non-reinfection cases (OR 1.701, 95\% CI 1.2492.315). This showed that the patients infected with CoxA16 were less prone to reinfection, although other enteroviruses were more likely to cause reinfection.

Two studies $[14,18]$ both found two HFMD patients infected twice with EV71. Xie et al. [19] also reported one patient infected with EV71 twice and one patient infected with Cox A16 twice. In the present study, two patients were infected with EV71 twice, and three patients were infected with Cox A16 twice. EV71 and Cox A16 have several genogroups [20-22], and more than one genogroup of EV71 or Cox A16 virus can occur simultaneously in an epidemic. Based on molecular typing, EV71 has been classified into three genotypes (A, B, and C) based on a partial VP1 sequence analysis [6], and in patients infected with genogroup B or C EV71 virus, cross-protection against genogroup A is not guaranteed [23]. Therefore, cross-infection among patients with the different genogroups of EV71 or Cox A16 virus is possible.

In the present study, $2-5 \%$ of patients underwent laboratory testing; therefore, laboratory results for both infections were available for only a few reinfection cases. Moreover, the samples of two patients infected with the same virus subtype in both infections could not be collected for sequence analysis. Further research emphasising key strata theory is warranted.

\section{Conclusion}

This study indicated that the reinfection rate of HMFD in Wuxi from 2008 to 2016 was $6.01 \%$. The population susceptible to HFMD reinfection was boys younger than 4 years of age who live in urban areas. It is important that administrations develop targeted health education and interventions to reduce the reinfection rate in susceptible populations.

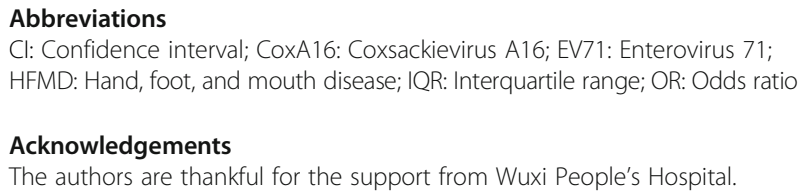

This research was supported by the National Natural Science Foundation of China (No. 81402732), Wuxi project of Science and Technology (No. CSE31N1515), Jiangsu Project of Preventive Medicine (No. Y2015006), Wuxi Key Medical Disciplines (No.ZDXK009), Wuxi Project of Key Medical Talents (No. ZDRC003), and Wuxi Project of Young Medical Talents (No. QNRC008).

\section{Authors' contributions}

CS coordinated field epidemiology, all data analysis, and manuscript writing. CS and $J$ analysed the data and wrote the manuscript. PS and $\mathrm{HJ}$ conducted field investigation and data collection. CS, JL and HJ performed the statistical analysis. CS, JL, and PS revised the paper and improved the technical quality of the manuscript. YS and YHQ were the project coordinator, responsible for the project design and implementation, and supervised all aspects of fieldwork, laboratory activities and data analysis. All authors approved the final version of the paper.

\section{Ethics approval and consent to participate}

This investigation was conducted by public health agencies as part of their legally authorised mandate and was therefore considered minimal-risk research and was exempted from ethical approval by the Institutional Review BoardWuxi Center for Disease Control and Prevention.

\section{Consent for publication}

Not applicable.

\section{Competing interests}

The authors declare that they have no competing interests.

\section{Publisher's Note}

Springer Nature remains neutral with regard to jurisdictional claims in published maps and institutional affiliations.

\section{Author details}

${ }^{1}$ Wuxi Center for Disease Control and Prevention, Wuxi 214023, Jiangsu, China. ${ }^{2}$ Jiangsu Center for Disease Control and Prevention, Nanjing 210009, Jiangsu, China.

Received: 2 February 2018 Accepted: 14 September 2018

Published online: 19 September 2018

\section{References}

1. Lu B, Guo H, Lu H. Hand, foot, and mouth disease in mainland China. Lancet Infect Dis. 2014;14(11):1041.

2. Pérezvélez CM, Anderson MS, Robinson CC, McFarland EJ, Nix WA, et al. Outbreak of neurologic enterovirus type 71 disease: a diagnostic challenge. Clin Infect Dis. 2007;45(8):950-7.

3. World Health Organization. WPRO A guide to clinical management and public health response for hand, foot and mouth disease (HFMD). Geneva: WHO Press; 2011.

4. Liu W, Wu S, Xiong X, Li T, Wen Z, Yan N, et al. Co-circulation and genomic recombination of coxsackievirus $\mathrm{A} 16$ and enterovirus 71 during a large outbreak of hand, foot, and mouth disease in Central China. PLoS One. 2014;9(4):e96051.

5. Hii YL, Rocklöv J, Ng N. Short term effects of weather on hand, foot and mouth disease. PLoS One. 2011;6(2):e16796. 
6. Brown BA, Oberste MS, Alexander JP Jr, Kennett ML, Pallansch MA. Molecular epidemiology and evolution of enterovirus 71 strains isolated from 1970 to 1998. J Virol. 1999;73(12):9969.

7. Michos AG, Syriopoulou VP, Hadjichristodoulou C, Daikos GL, Lagona E, Douridas P, et al. Aseptic meningitis in children: analysis of 506 cases. PLoS One. 2007;2(7):e674.

8. Solomon T, Lewthwaite P, Perera D, Cardosa MJ, McMinn P, Ooi MH Virology, epidemiology, pathogenesis, and control of enterovirus 71. Lancet Infect Dis. 2010;10(11):778-90.

9. Chan LG, Parashar UD, Lye MS, Ong FG, Zaki SR, Alexander FP, et al. Deaths of children during an outbreak of hand, foot, and mouth disease in Sarawak, Malaysia: clinical and pathological characteristics of the disease. For the Outbreak Study Group. Clin Infect Dis. 2000;31(3):678-83.

10. Wu TN. An epidemic of enterovirus 71 infection in Taiwan. N Engl J Med. 1999:341(13):929.

11. Ang LW, Koh BK, Chan KP, Chua LT, James L, Goh KT. Epidemiology and control of hand, foot and mouth disease in Singapore, 2001-2007. Ann Acad Med Singap. 2009;38(2):106.

12. Zhang Y, Zhu Z, Yang W, Ren J, Tan X, Wang Y, et al. An emerging recombinant human enterovirus 71 responsible for the 2008 outbreak of hand foot and mouth disease in Fuyang city of China. Virol J. 2010;7(1):94

13. Huang EV, Huang LM, Kao VL, Lu VY, Shao PL, Cheng SL, et al. Seroprevalence of enterovirus 71 and no evidence of crossprotection of enterovirus 71 antibody against the other enteroviruses in kindergarten children in Taipei city. J Microbiol Immunol Infect. 2012;45(2):96.

14. Chen GP, Wu JB, Wang JJ, Pan HF, Zhang J, Shi YL, et al. Epidemiological characteristics and influential factors of hand, foot and mouth disease (HFMD) reinfection in children in Anhui province. Epidemiol Infect. 2016; 144(1):153-60

15. Xie Z, Wang L, Yan Y, Hong R, Ou J, Huang W, et al. A cohort study on the characteristics of the recurrent epidemics on hand, foot and mouth disease, in Fujian province. Zhonghua Liu Xing Bing Xue Za Zhi. 2014;35(10):1109.

16. Mao YJ, Sun L, Xie JG, Yau KK. Epidemiological features and spatio-temporal clusters of hand-foot-mouth disease at town level in Fuyang, Anhui Province, China (2008-2013). Epidemiol Infect. 2016;144(15):3184-97.

17. Ji H, Li L, Liu Y, Ge H, Wang X, Hu J, et al. Seroepidemiology of human enterovirus71 and coxsackievirusA16 in Jiangsu province, China. Virol J. 2012;9(1):248.

18. Chen C, Xiao X, Ding P. Analysis of repeated infection in hand-foot-mouth disease cases in Guangzhou from 2008 to 2011. China Trop Med. 2012;12(8): 934-6.

19. Xie Z, Zhang Y, Yan Y, Hong R, Wang L. Preliminary study on recurrence with viruses causing hand foot and mouth disease. Dis Surveillance. 2013; 28(9):735-9.

20. Li L, He Y, Yang H, Zhu J, Xu X, Dong J, et al. Genetic characteristics of human enterovirus 71 and coxsackievirus A16 circulating from 1999 to 2004 in Shenzhen, People's Republic of China. J Clin Microbiol. 2005;43(8):3835.

21. Perera D, Yusof MA, Podin Y, Ooi MH, Thao NT, Wong KK, et al. Molecular phylogeny of modern coxsackievirus A16. Arch Virol. 2007;152(6):1201-8.

22. Zhang Y, Wang D, Yan D, Zhu S, Liu J, Wang H, et al. Molecular evidence of persistent epidemic and evolution of subgenotype B1 coxsackievirus A16associated hand, foot, and mouth disease in China. J Clin Microbiol. 2010; 48(2):619-22.

23. Huang ML, Chiang PS, Chia MY, Luo ST, Chang LY, Lin TY, et al. Crossreactive neutralizing antibody responses to enterovirus 71 infections in young children: implications for vaccine development. PLoS Negl Trop Dis. 2013;7(2):e2067.

Ready to submit your research? Choose BMC and benefit from:

- fast, convenient online submission

- thorough peer review by experienced researchers in your field

- rapid publication on acceptance

- support for research data, including large and complex data types

- gold Open Access which fosters wider collaboration and increased citations

- maximum visibility for your research: over $100 \mathrm{M}$ website views per year

At $\mathrm{BMC}$, research is always in progress.

Learn more biomedcentral.com/submissions 